\title{
Development and Standardization of Instant Food Mixes from Dehydrated Pumpkin and Pumpkin Seed Powder (Cucurbita moschata Duch ex Poir)
}

\author{
Anju K. Dhiman, Vidya Negi, Surekha Attri and Preethi Ramachandran*
}

Dept. of Food Science and Technology, College of Horticulture, Dr. Y. S. Parmar University of Horticulture and Forestry, Nauni Solan, H.P. (173 230), India

\section{Corresponding Author}

Preethi Ramachandran

e-mail: preethir615@gmail.com

\author{
Article History \\ Manuscript No. AR1792 \\ Received in $21^{\text {st }}$ January, 2017 \\ Received in revised form $22^{\text {nd }}$ March, 2017 \\ Accepted in final form $6^{\text {th }}$ April, 2017
}

\begin{abstract}
Studies were carried out in the Department of Food Science and Technology, Dr. Y.S. Parmar University of Horticulture and Forestry, Nauni, Solan, Himachal Pradesh during the months of December 2013 to July 2014 for the development of instant food mixes (IMF) from dehydrated pumpkin and its seed flour. Dehydrated Pumpkin in the form of shreds, fine powder and granulated powder was used for the development of instant halwa mix, instant soup mix and instant porridge mix with better nutritional attributes. Instant halwa mix prepared

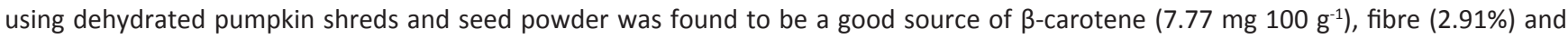
protein (5.04\%). While among all the instant halwa mixes prepared by using different forms of dehydrated pumpkin and its seed flour, ready-to-serve halwa prepared from granulated powder was much preferred by the panellist during sensory evaluation. Instant soup mix (ISM) developed by using pumpkin powder with various starch sources (rice starch, corn starch and potato starch), however, did not show much variation in chemical composition but ISM prepared with rice starch was most liked by the panellist. Instant porridge mixes prepared from broken wheat and pumpkin powder in the ratio of 60:40 was rated as the best by the panellist and was observed to contain highest

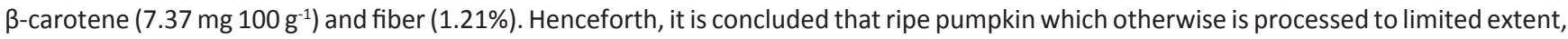
can be successfully utilized for the production of good quality and nutritionally enriched IMF.
\end{abstract}

Keywords: Pumpkin, seed flour, drying, IFM, IHM, IPM and ISM

\section{Introduction}

The term 'instant food mix' implies to simple, convenient and fast to prepare food products, in which some of the ingredients are premixed by providing an easy and readily available homemade option. They comprise of processed cereals, pulses, condiments, spices or any other food in varying combinations. Instant mixes helps to save very important resources such as time and energy and hence, provide great convenience to home makers who are in job and have multifarious work participation. Instant mixes have the potential to contribute as nutritious food because of their high dietary fibre content and other health benefits. Several technologies have been developed to standardize and commercialize ready-to-eat (RTE) mixes of traditional or popular Indian foods. These include instant khadi mix (Sharma et al., 1995), instant khichadi mix (Patki et al., 2002), instant rava idli mix (Madhura et al., 1998), instant vegetable pulav mix (Semwal et al., 2001), instant sooji upma mix (Premavalli et al., 1987) and instant dhokla mix (Lohekar and Arya, 2014). Pumpkin in form of shreds, granulated powder and fine powder and its seed powder after defatting can be used as nutritional supplements in the production of various instant food mixes such as halwa, soup and porridge that are ready to cook and are in great demand in present market.

Pumpkin is a valuable source of functional components like lutein, zeaxanthin, vitamin E, ascorbic acid, phytosterols, selenium and linoleic acid which act as antioxidant in human nutrition (Philips et al., 2005; Applequist et al., 2006; Glew et al., 2006). It is a good source of vitamins, mineral salts, pectin and other substances that are beneficial to health. Pumpkin provide medicinal power, which act as anti-inflammatory, diuretic and emulsifier and thus helps in treatment of fever, ear pain, inflammation of urinary bladders and prostrate disorder. Pumpkin has a vast scope of diversification and can be utilized in the production of various processed products like jam, pickle, beverages, candy, bakery products and confectionary (Dhiman et al., 2009). Pumpkin can be processed into powder which has longer shelf life and therefore, it can be used to supplement cereal flours in bakery products, breads (Ratnayake et al., 2004), cookies, 
cakes (Pongjanta et al., 2006), soup, sauces, instant noodle, instant pumpkin kofta as well as natural colouring agent in pasta and flour mix. Therefore, attempts have been made in this experiment to prepare instant food mixes from pumpkin and its seed flour.

\section{Materials and Methods}

Development and standardization of instant food mixes like instant halwa mix (IHM), instant soup mix (ISM) and Instant Porridge Mix (IPM) from dehydrated pumpkin were conducted in the Department of Food Science and Technology, Dr. Y.S. Parmar University of Horticulture and Forestry, Nauni, Solan (HP) during the December 2013-July 2014. The study was divided into various experiments comprising of different treatments and each treatment being replicated thrice.

\subsection{Selection and procurement of ingredients}

The ingredients used for the development of instant food mixes where procured from the local market of Solan, Himachal Pradesh, India. The ingredient used for the development of the various instant food mixes were ripe pumpkin, broken wheat, tomato, pea, moong dhal, spinach, carrot, sugar, salt, milk powder (Nestle dairy milk powder), ghee, different spices, starch, etc.

2.2. Preparation of pumpkin shreds, granulated powder, fine powder and pumpkin seed flour

2.2.1. Dehydrated pumpkin shreds, granulated and fine powder

Ripe pumpkin fruits were washed and cut into halves. After removing the seeds and fluffy portion (fibrous strains/brains), pumpkin was cut into slices. These slices were peeled and grated into shreds. The shreds were steam blanched for 4 minutes followed by dipping in 500 ppm of potassium metabisulphite (KMS) solution for 15 minutes. The shreds were then dried in a mechanical dehydrator at $60 \pm 2{ }^{\circ} \mathrm{C}$ for 8 to10 hours. The dried shreds were ground by using a grinder followed by sieving through 90 and 48 mesh metallic sieves to yield granulated powder and fine powder, respectively. The dried shreds prepared, granulated powder and fine powder were packed in polyethylene pouches (PEP) for further use.

\subsubsection{Pumpkin seed powder}

The seeds were washed, oven-dried $\left(60{ }^{\circ} \mathrm{C}\right.$ for two hours) and manually decorticated. It was then crushed by using a mechanical grinder and was soaked in $n$-hexane for 36 hours with change of solvent after every 8 hours for de-fatting the kernels. The defatted crushed kernels were kept on filter paper to remove the extra $n$-hexane, then, these seeds were dried at room temperature and ground and passed through a 355 mesh sieve to get seed powder. The powder was packed in Polyethylene pouches and stored at ambient temperature for further use in preparation of IHM.

\subsubsection{Dehydration of vegetables for preparation of ISM}

The different vegetables like carrot, peas, tomato, carrot, spinach, onion, ginger and garlic were dried according to the method as described by Lal et al. (1986). After drying vegetables were packed in Polyethylene pouches for further use in ISM.

\subsubsection{Preparation of broken wheat}

The procured broken wheat was converted into small granules by using mechanical grinder followed by sieving through 300 $\mu \mathrm{m}$ (IS) size metallic sieve.

\subsection{Development of instant food mixes from dehydrated} pumpkin and pumpkin seed powder

\subsubsection{Instant halwa mix (IHM)}

2.3.1.1. Development and standardization of recipe for preparation of IHM

The best four recipes (Table 1) after conducting the preliminary studies and using sensory evaluation by a panel of ten judges,

Table 1: Formulation of recipes for IHM from different forms dehydrated pumpkin and its seed powder

\begin{tabular}{llc}
\hline Treatments & Ingredients & Quantity $(\mathrm{g})$ \\
\hline $\mathrm{T}_{1}$ & Pumpkin granulated powder & 100 \\
& Sugar powder & 79 \\
& Milk powder & 50 \\
$\mathrm{~T}_{2}$ & Pumpkin shreds & 100 \\
& Sugar powder & 86 \\
& Milk powder & 50 \\
$\mathrm{~T}_{3}$ & Pumpkin granulated powder: & 100 \\
& seed powder (2:1) & \\
& Sugar powder & 79 \\
& Milk Powder & 50 \\
$\mathrm{~T}_{4}$ & Dehydrated pumpkin shreds: & 100 \\
& seed powder (2:1) & 86 \\
& Sugar powder & 50 \\
\hline
\end{tabular}

were selected for the development of IHM.

\subsubsection{Procedure for preparation of IHM for packaging}

The base ingredients such as pumpkin shreds, pumpkin granulated powder and pumpkin seed powder were roasted separately in an open pan for 2-3 minutes or till light brown colour and was then allowed to cool at room temperature. The formulations of different treatments using pumpkin in various forms were then mixed properly with powdered sugar and milk powder as per the standardized recipe.

\subsubsection{Standardization of method for preparation of ready-} to-serve pumpkin halwa

The method for standardized preparation of ready-to-serve halwa from IHM includes boiling of required amount of water in an open pan. IHM was then added in boiling water and was 
stirred continuously, followed by addition of ghee. Continuous cooking was done till it leaves oil.

\subsubsection{Instant soup mix (ISM)}

2.3.2.1. Development and standardization of recipe for preparation of ISM

The basic recipe for preparation of ISM was standardized by using ingredients such as roasted fine pumpkin powder, roasted moong dhal powder, tomato powder, salt, ginger powder, garlic powder, onion powder, black pepper powder, dried peas, dried spinach and dried carrots (Table 2). Four different recipes were tried by changing the proportion

Table 2: Development and standardization of recipe for preparation of instant soup mix

\begin{tabular}{lcccc}
\hline Ingredients (g) & \multicolumn{4}{c}{ Recipes } \\
\cline { 2 - 5 } & Recipe 1 & Recipe 2 & Recipe 3 & Recipe 4 \\
\hline $\begin{array}{l}\text { Roasted pump- } \\
\text { kin powder }\end{array}$ & 20 & 20 & 20 & 20 \\
$\begin{array}{l}\text { Roasted moong } \\
\text { dhal powder }\end{array}$ & 5 & 5 & 5 & 5 \\
Tomato powder & 12 & 13 & 15 & 16 \\
Salt & 6 & 7 & 8 & 8.5 \\
Ginger powder & 0.70 & 0.80 & 0.85 & 0.90 \\
Garlic powder & 0.70 & 0.80 & 0.85 & 0.90 \\
Onion powder & 0.70 & 0.80 & 0.85 & 0.90 \\
Black pepper & 0.75 & 0.85 & 0.85 & 0.90 \\
powder & & & & \\
Dried pea & 2 & 2 & 2 & 2 \\
Dried spinach & 2 & 2 & 2 & 2 \\
Dried carrot & 2 & 2 & 2 & 2 \\
\hline The select recipe was & & & & \\
\hline
\end{tabular}

The selected recipe was blended with constant amount (10 g) each of different starch such as rice starch $\left(T_{1}\right)$, corn starch $\left(T_{2}\right)$ and potato starch $\left(T_{3}\right)$

of ingredients and the prepared soups were subjected to organoleptic evaluation by a panel of 10 semi trained judges. The highly accepted soup was selected as base recipe for variation to conduct further studies.

\subsubsection{Procedure for preparation of ISM for packaging}

The method of preparation of ISM was standardized by roasting pumpkin powder and moong dhal in an open pan and then allowing it to cool at room temperature. Different ingredients like tomato powder, ginger powder, garlic powder, black pepper powder, cumin powder, dehydrated spinach and dried peas were mixed properly. The mixture was divided into three different lots and blended with rice starch $\left(T_{1}\right)$, corn starch $\left(T_{2}\right)$ and potato starch $\left(T_{3}\right)$.

2.3.2.3. Standardization of method for preparation of ready- to-serve pumpkin soup

The method standardized for the preparation of Ready-toServe soup from ISM was boiling required amount of water in a pan and adding ISM in boiling water and continuous boiling was done. Butter can be added to enhance taste.

\subsubsection{Instant porridge mix (IPM)}

\subsubsection{Standardization of recipe for preparation of IPM}

From the preliminary studies conducted, four best recipes using broken wheat, moong dhal powder, milk powder and sugar powder (Table 3) were subjected to organoleptic evaluation by a panel of ten judges. The recipe, which received the highest rating for overall acceptability was selected for

Table 3: Formulation of recipes for preparation of instant porridge mix

\begin{tabular}{lcccc}
\hline Ingredients (g) & Recipe 1 & Recipe 2 & Recipe 3 & Recipe 4 \\
\hline Broken Wheat & 50 & 50 & 50 & 50 \\
Moong dhal & 10 & 10 & 10 & 10 \\
powder & & & & \\
Milk powder & 10 & 15 & 20 & 25 \\
Sugar powder & 15 & 20 & 25 & 30 \\
\hline
\end{tabular}

further studies in which broken wheat was replaced with different proportion of pumpkin powder (Table 4). Six different formulations were prepared by mixing various ingredients. IPM prepared from these formulation were subjected to sensory evaluation by a panel of judges in order to select the

Table 4: Formulation of instant porridge mix with different proportion of dehydrated pumpkin powder

\begin{tabular}{lcccccc}
\hline Ingredients (g) & \multicolumn{7}{c}{ Formulations } \\
\cline { 2 - 7 } & 1 & 2 & 3 & 4 & 5 & 6 \\
\hline Broken Wheat & 100 & 90 & 80 & 70 & 60 & 50 \\
$\begin{array}{l}\text { Pumpkin pow- } \\
\text { der }\end{array}$ & - & 10 & 20 & 30 & 40 & 50 \\
Moong d hal & 10 & 10 & 10 & 10 & 10 & 10 \\
powder & & & & & & \\
Milk powder & 20 & 20 & 20 & 20 & 20 & 20 \\
Sugar powder & 25 & 25 & 25 & 25 & 25 & 25 \\
\hline
\end{tabular}

best three for further studies. Out of these six formulations 3,4 and 5 were awarded highest rating by the panel of judges and referred as treatment $T_{1}, T_{2}$ and $T_{3}$, for further studies.

2.3.3.2. Standardization of method for preparation of IPM for packaging

The method standardized for the preparation of IPM for packaging included roasting of pumpkin powder, broken wheat and moong dhal powder separately in an open pan and allowing the contents to cool at room temperature. 
2.3.3.3. Standardization of method for preparation of readyto-serve pumpkin porridge

The method standardized for the preparation of ready-toserve porridge from IPM included boiling of required amount of water in a pan followed by adding IPM in boiling water with constant stirring boiling till done. Ghee (deshi) was added to enhance the palatability.

\subsection{Physico-chemical, sensory and statistical analysis}

Moisture was estimated by drying the weighed sample (10 g) to a constant weight in a hot air oven. The titratable acidity was expressed as per cent citric acid (AOAC, 2004) and estimated by using phenolphthalein as an indicator to give pink colour (end point). Ascorbic acid content was determined as per AOAC (2004) method using 2, 6-dichlorophenol-indophonol dye. Total sugars and reducing sugars were determined as per the method described by Ranganna (2009). Method given by Ranganna (2009) was followed to determine the $\beta$-carotene and crude fibre of various ingredients and the developed products. The amount of crude fat the different samples and water activity of the prepared products was determined by using Soxhlet extraction apparatus and Computer digital water activity meter ( $\mathrm{HW}_{3}$ model, Rotronic International, Switzerland), respectively. The different parameters for sensory evaluation such as colour, taste, texture and overall acceptability were done by using 9-point hedonic scale by the panel of ten semi trained judges. The data for quantitative analysis of various physico-chemical attributes were analyzed by completely randomized design (CRD) while the data on sensory analysis were analyzed by randomized block design (RBD).

\section{Results and Discussion}

\subsection{Proximate composition of raw material}

The data pertaining to proximate composition of pumpkin powder, defatted pumpkin seed powder and broken wheat used in the study for development of instant mixes are presented in Table 5. It was observed that pumpkin powder was rich in fiber $(2.91 \pm 0.01 \%)$ and $\beta$-carotene $(7.77 \pm 0.31 \%)$ whereas seed powder contained high amount of protein

Table 5: Chemical characteristics of raw materials

\begin{tabular}{lccc}
\hline Characteristics & PP & DPSP & BW \\
\hline Moisture (\%) & $6.09 \pm 0.04$ & $4.97 \pm 0.01$ & $10.15 \pm 0.02$ \\
Protein (\%) & $5.04 \pm 0.06$ & $34.31 \pm 0.01$ & $8.45 \pm 0.20$ \\
Fat (\%) & $2.73 \pm 0.28$ & $3.12 \pm 0.02$ & $2.11 \pm 0.03$ \\
Crude Fiber (\%) & $2.91 \pm 0.01$ & $0.19 \pm 0.15$ & $1.73 \pm 0.02$ \\
$\beta$-carotene (mg 100 & $7.77 \pm 0.31$ & $0.86 \pm 0.01$ & $1.93 \pm 0.003$ \\
$\mathrm{~g}^{-1}$ ) & & & \\
Total sugars (\%) & $40.32 \pm 0.75$ & $3.22 \pm 0.01$ & $16.21 \pm 0.22$ \\
Reducing sugars (\%) & $16.40 \pm 0.05$ & $0.38 \pm 0.01$ & $3.55 \pm 0.02$ \\
\hline
\end{tabular}

PP: Pumpkin powder (Mean \pm SE); DPSP: Defatted pumpkin seed powder (Mean \pm SE); BW: Broken wheat (Mean \pm SE)
(34.31 $\pm 0.01 \%)$ and fat $(3.12 \pm 0.02 \%)$.

\subsection{Development and Standardization of instant food mixes from Dehydrated pumpkin}

\subsubsection{Instant halwa mixes}

3.2.1.1. Standardization of method for preparation of readyto-serve pumpkin halwa

An amount of $200 \mathrm{~g}$ of IHM from pumpkin granulated powder $\left(T_{1}\right)$ required $1500 \mathrm{ml}$ of water and 10 minutes of cooking time which yield 5 servings. Similar amount of water and cooking time was optimized for ready-to-serve halwa from the pumpkin granulated powder+seed powder $\left(\mathrm{T}_{2}\right)$. While IHM from dehydrated pumpkin shreds $\left(T_{3}\right)$ and dehydrated pumpkin shreds + seed powder $\left(T_{4}\right)$ required $2000 \mathrm{ml}$ of water and 12 minutes of cooking time to yield 5 servings ready-toserve halwa.

\subsubsection{Nutritional evaluation of instant halwa mix}

The nutritional composition of the instant halwa mix is summarized in Table 6 . The moisture content of the halwa mix ranged from 4.33 to $4.72 \%$. The total sugar content of the mix was 41.52 and $41.86 \%$ for halwa prepared from granulated powder and pumpkin shreds, respectively,

\begin{tabular}{|c|c|c|c|c|c|}
\hline \multicolumn{6}{|c|}{ Table 6: Nutritional composition of instant halwa mix } \\
\hline \multirow[t]{2}{*}{ Nutrients } & \multicolumn{4}{|c|}{ Treatments } & \multirow{2}{*}{$\begin{array}{c}C D \\
(p=0.05)\end{array}$} \\
\hline & $\mathrm{T}_{1}$ & $\mathrm{~T}_{2}$ & $\mathrm{~T}_{3}$ & $\mathrm{~T}_{4}$ & \\
\hline Moisture (\%) & 4.33 & 4.72 & 4.49 & 4.34 & 0.01 \\
\hline Total sugar (\%) & 41.52 & 41.86 & 43.46 & 43.55 & 0.10 \\
\hline $\begin{array}{l}\text { Reducing sugar } \\
\text { (\%) }\end{array}$ & 12.48 & 13.58 & 14.39 & 14.58 & 0.03 \\
\hline Protein (\%) & 6.85 & 6.70 & 14.00 & 14.11 & 0.08 \\
\hline $\begin{array}{l}\beta \text {-carotene } \\
\left(\mathrm{mg} 100 \mathrm{~g}^{-1}\right)\end{array}$ & 6.48 & 7.62 & 6.07 & 7.17 & 0.06 \\
\hline Crude fat (\%) & 5.98 & 5.94 & 7.04 & 7.04 & 0.02 \\
\hline Crude fiber (\%) & 1.00 & 1.04 & 1.08 & 1.09 & 0.07 \\
\hline Water activity & 0.396 & 0.425 & 0.423 & 0.407 & 0.001 \\
\hline
\end{tabular}

whereas those containing seed powder had slightly higher sugar i.e., 43.46 and $43.55 \%$ in pumpkin shreds and pumpkin powder, respectively. The protein content of the halwa was $6.85,6.70,14.00$ and 14.11 for $T_{1}, T_{2}, T_{3}$ and $T_{4}$, respectively. The prepared halwa mixes from pumpkin powder and shred had lower fat content as compared to those that had seed powder added to pumpkin powder and shred. The water activity of each mix was lower than 0.6 i.e., they are safe from microbial contaminations.

\subsubsection{Sensory evaluation of instant halwa mix}

The data pertaining to effect of treatments on the colour, texture, flavour and overall acceptability of IHM is given in Figure 1 . The figure clearly indicated that among different treatments mean maximum and minimum score for overall acceptability was recorded in $T_{1}(8.04)$ and $T_{3}(7.16)$, 


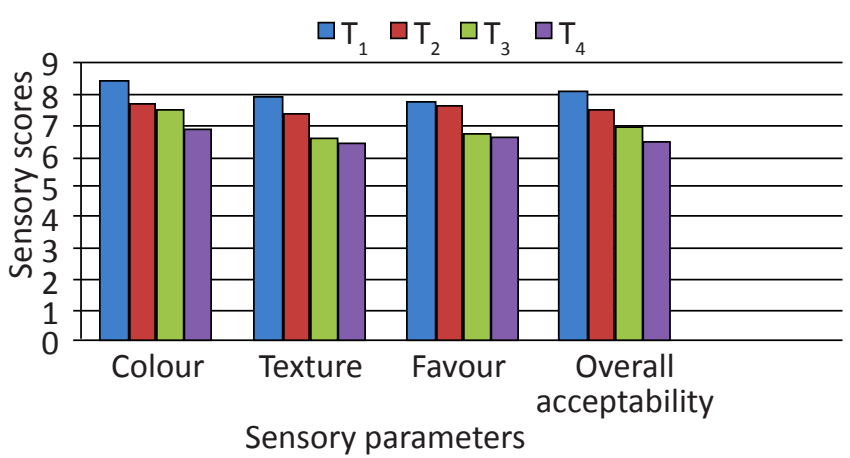

Figure 1: Sensory evaluation of ready-to-serve Instant halwa mix prepared from different forms of dehydrated pumpkin and is seed powder

respectively. Hence, ready-to-serve halwa from granulated pumpkin powder was more liked by the panel as compared to other treatments, but still all the treatments were in the acceptable limits.

\subsubsection{Instant soup mix}

\subsubsection{Sensory evaluation}

The soup mixes prepared from four different recipes were subjected to a panel of ten judges for sensory evaluation. Based upon the highest overall acceptability score (7.89) (Figure 2). Recipe 3 was selected as base recipe for the addition of different starch.

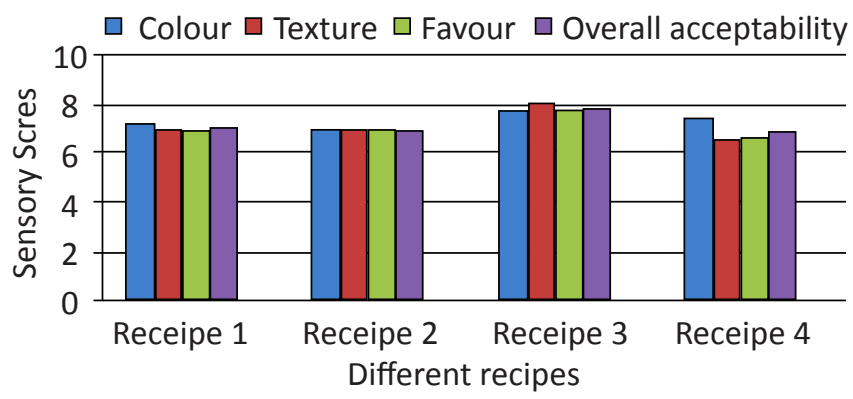

Figure 2: Sensory evaluation of instant soup mix (on 9 point hedonic scale) from pumpkin powder

The standard recipe with highest overall acceptability score was taken as base and different starch sources were added at constant rate. The recipe with rice starch was referred as $\mathrm{T}_{1}$, corn starch $\mathrm{T}_{2}$ and potato starch as $\mathrm{T}_{3}$.

\subsubsection{Standardization of method for preparation of ready-} to-serve pumpkin soup

For every $60 \mathrm{~g}$ of ISM $750 \mathrm{ml}$ of water was required. The cooking time ranged from 2 to 3 minutes and the final product yield was $750 \mathrm{ml}$ approximately 5 servings (150 $\mathrm{ml}$ each).

\subsubsection{Nutritional evaluation of instant soup mix}

The nutritional composition of Instant soup mix is presented in Table 7. It was observed that the mix was rich in protein (6.50-6.65\%), $\beta$-carotene (6.92-7.01 mg $100 \mathrm{~g}^{-1}$ ) and crude fiber (1.09-1.24\%). Total sugar were found to be $37.48,39.85$

\begin{tabular}{|c|c|c|c|c|}
\hline \multirow[t]{2}{*}{ Nutrients } & \multicolumn{3}{|c|}{ Treatments } & \multirow{2}{*}{$\begin{array}{c}C D \\
(p=0.05)\end{array}$} \\
\hline & $\mathrm{T}_{1}$ & $\mathrm{~T}_{2}$ & $\mathrm{~T}_{3}$ & \\
\hline Moisture (\%) & 4.48 & 4.91 & 4.67 & 0.01 \\
\hline Total sugar (\%) & 37.48 & 39.85 & 39.63 & 0.03 \\
\hline Reducing sugar (\%) & 10.26 & 12.31 & 15.45 & 0.05 \\
\hline Protein (\%) & 6.50 & 6.65 & 6.52 & 0.09 \\
\hline$\beta$-carotene (mg $100 \mathrm{~g}^{-1}$ ) & 6.92 & 7.01 & 6.99 & 0.04 \\
\hline Crude fat (\%) & 4.38 & 4.44 & 4.68 & 0.02 \\
\hline Crude fiber (\%) & 1.09 & 1.24 & 1.12 & 0.001 \\
\hline Water activity & 0.339 & 0.341 & 0.356 & 0.001 \\
\hline
\end{tabular}

and $39.63 \%$ in instant soup mix containing rice starch, corn starch and potato mix, respectively.

3.2.2.4. Sensory evaluation of instant soup mix with different starch source

It is clear from the Figure 3 that among different treatments

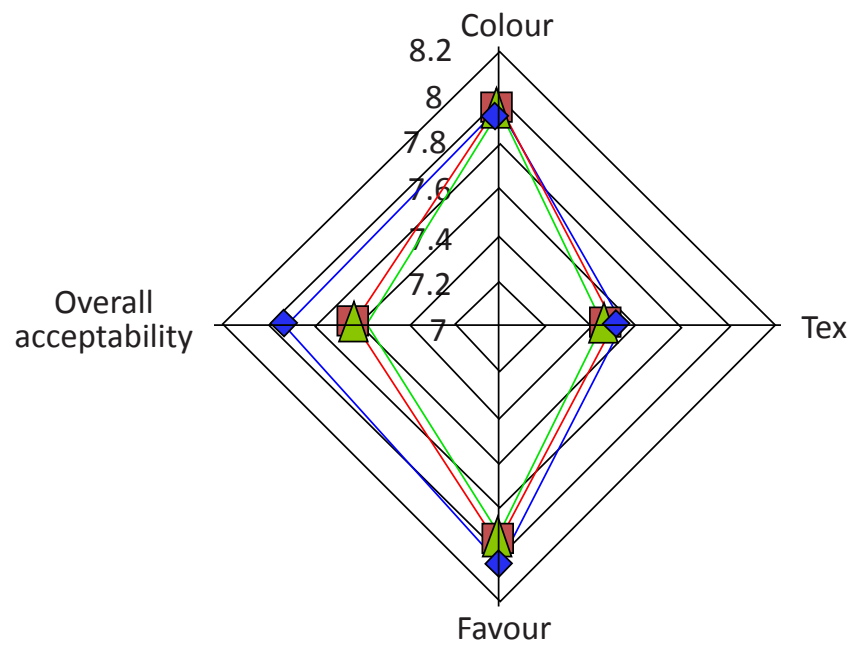

Figure 3: Sensory evaluation of instant soup mix (on 9 point hedonic scale) from pumpkin powder and starch sources

maximum and minimum score for overall acceptability was recorded in $T_{1}(7.88)$ and $T_{3}(7.16)$, respectively.

\subsubsection{Instant porridge mix (IPM)}

\subsubsection{Sensory evaluation}

The data of sensory evaluation for four best recipes after preliminary studies are depicted in Table 8 showed that the highest score (7.55) for overall acceptability was awarded to Recipe 3.

This recipe was taken as base for preparation of six different formulations with varied proportion of broken wheat and pumpkin powder. Based upon the higher overall acceptability scores (Figure 4) three formulations i.e., 3, 4 and 5 were selected for nutritional studies and referred as $T_{1}, T_{2}$ and $T_{3}$, respectively. 


\begin{tabular}{lcccc}
\hline \multicolumn{5}{l}{ Table 8: Sensory evaluation of IPM (on 9 point hedonic scale) } \\
\hline Recipe & Colour & Texture & Flavour & Overall acceptability \\
\hline Recipe 1 & 7.25 & 7.05 & 7.00 & 7.10 \\
Recipe 2 & 7.48 & 7.15 & 7.23 & 7.28 \\
Recipe 3 & 7.83 & 7.33 & 7.50 & 7.55 \\
Recipe 4 & 7.51 & 7.18 & 7.32 & 7.33 \\
CD & 0.01 & 0.02 & 0.10 & 0.02 \\
$(p=0.05)$ & & & & \\
\hline
\end{tabular}

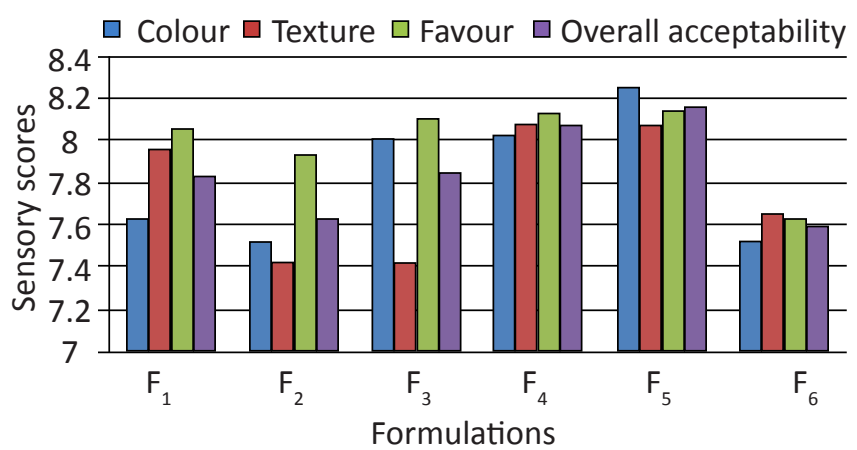

Figure 4: Sensory evaluation of instant porridge mix (on 9 point hedonic scale)

\subsubsection{Standardization of method for preparation of ready- to-serve pumpkin porridge}

For the preparation of ready-to-Serve porridge (155 g) 800 $\mathrm{ml}$ of water was required. The cooking time ranged from 5 to 6 minutes, and the final product recovery was $(650 \mathrm{~g})$ i.e., approximately 5 servings ( $125 \mathrm{~g}$ ).

\subsubsection{Nutritional evaluation of instant soup mix}

Freshly prepared instant porridge mix had moisture, 4.27-4.52; total protein, 11.43-12.22; $\beta$-carotene, 5.77-7.77; crude fat, 6.79-6.92; total sugar, 30.29-30.98; crude fibre, 1.09-1.24 and water activity, 0.335-0.375 (Table 9). There

Table 9: Nutritional composition of instant porridge mix

\begin{tabular}{lcccc}
\hline Nutrients & \multicolumn{3}{c}{ Treatments } & CD \\
\cline { 2 - 4 } & BW1 & BW2 & Bw3 & $(p=0.05)$ \\
\hline Moisture (\%) & 4.27 & 4.31 & 4.52 & 0.01 \\
Total sugar (\%) & 30.29 & 30.72 & 30.98 & 0.06 \\
Reducing sugar (\%) & 10.22 & 10.76 & 11.14 & 0.05 \\
Protein (\%) & 12.22 & 12.12 & 11.43 & 0.06 \\
B-carotene (mg 100 g $\left.{ }^{-1}\right)$ & 5.77 & 6.27 & 7.77 & 0.05 \\
Crude fat (\%) & 6.79 & 6.86 & 6.92 & NS \\
Crude fiber (\%) & 1.09 & 1.12 & 1.24 & 0.01 \\
Water activity & 0.335 & 0.387 & 0.375 & 0.01 \\
\hline
\end{tabular}

BW1: Broken wheat: pumpkin powder (80:20); BW2: Broken wheat: pumpkin powder (70:30); BW3: Broken wheat : pumpkin powder (60:40) were no significant changes in these properties with the increased addition of pumpkin powder.

Lohekar and Arya (2014) also observed similar result that instant dhokla mix prepared by adding finger millet and garden cress seeds was found to contain more protein $(18.39 \mathrm{~g})$, fat $(4.95 \mathrm{~g})$ and fiber $(1.31 \mathrm{~g})$ similar to the instant food mixes prepared in this experiment.

\section{Conclusion}

IFM from dehydrated pumpkin was highly acceptable and rich in nutrition. IHM developed from dehydrated pumpkin shreds and seed powder in a ratio of 2:1 was high in $\beta$-carotene but the panel of judges favoured the halwa developed from granulated pumpkin powder on the basis of sensory evaluation. ISM formulated from pumpkin powder with rich starch was most liked by the panellist. Among different formulations developed for IPM, porridge from broken wheat and pumpkin powder in ratio of 60:40 was rated as best.

\section{Acknowledgment}

We gratefully acknowledge the financial support of the Department of Science and Technology (DST), New Delhi, India, through their Project "Development of low cost value added processed products from ripe pumpkin (Curcurbita moschata) and dissemination of technology to the farm women of Himachal Pradesh".

\section{References}

Applequist, W.L., Avula, B., Schaneberg, B.T., Wang, Y.H., Khan, I.A., 2006. Comparative fatty acid content of seeds of four Cucurbita species grown in a common garden. Journal of Food Composition Analysis 19, 606-611.

A.O.A.C., 2004. Official Methods of Analysis of theAssociation of Official Analytical Chemists ( $20^{\text {th }}$ Edn.), Association of Official Analytical Chemists, Washington DC, USA.

Dhiman, A.K., Sharma, K.D., Attri, S., 2009. Functional constituent and processing of pumpkin- a review. Journal of Food Science and Technology 46(5), 411-417.

Glew, R.H., Glew, R.S., Chuang, L.T., Huang, Y.S., Millson, M., Constans, D., Vanderjagt, D.J., 2006. Amino acid, mineral and fatty acid content of pumpkin seeds (Cucurbita spp) and Cyperus esculentus nuts in the Republic of Niger. Plant Foods for Human Nutrition 61, 51-60.

Lohekar, A.S., Arya, A.B., 2014. Development of value added Instant Dhokla Mix. International Journal of Food and Nutritional Sciences 4(3), 78-83.

Madhura, C.V., Premavalli, K.S., Arya, S.S., 1998. Studies on traditional Indian Foods-III. Development and storage stability of rava idli mix. Indian Food Packer 52, 33-37.

Patki, P.E., Srihari, P., Arya, S.S., 2002. Studies on development of instant whole legumes. Indian Food Packer 56, 72-79.

Phillips, K.M., Ruggio, D.M., Ashraf-Khorassani, M., 2005. Phytosterol composition of nuts and seeds commonly 
consumed in the United States. Journal of Agricultural and Food Chemistry 53, 9436-9445.

Pongjanta, J., Naulbunrang, A., Kawngdang, S., Manon, T., Thepjaikat, T., 2006. Utilization of pumpkin powder in bakery products. Journal of Science and Technology 28, 71-79.

Premavalli, K.S., Vidyasagar, K., Arya, S.S., 1987. Studies on traditional Indian foods: II. Development and storage stability of upma mix. Indian Food Packer 41, 23-30.

Ratnayake, W.S., Hoover, R., Shahidi, F., Parera, C., Jane, J., 2004. Composition, molecular structure and physicochemical properties of starches from field pea (Pisum sativum L.) cultivars. Food Chemistry 74, 189-202.

Ranganna, S., 2009. Handbook of analysis and quality control for fruit and vegetable products. Tata McGraw Hill, New Delhi, 1112.

Semwal, A.D., Sharma, G.K., Patki, P.E., Padmashree, A., Arya, S.S., 2001. Studies on development and storage stability of instant vegetable pulav mix. Journal of Food Science and Technology 38, 231-234.

Sharma, G.K., Semwal, A.D., Arya, S.S., 1995. Development of instant kadhi mix. Journal of Food Science and Technology 32, 206-210. 